\title{
Tgf $\beta$-Smad and MAPK signaling mediate scleraxis and proteoglycan expression in heart valves
}

\author{
Damien N. Barnette, BS ${ }^{a, b, c}$, Alexia Hulin, PhD ${ }^{d}$, A.S. Ishtiaq Ahmed, $\mathbf{P h D}^{\mathrm{e}}$, Alain C. Colige, \\ PhD $^{\mathrm{d}}$, Mohammed Azhare ${ }^{\mathrm{e}}$, and Joy Lincoln, PhD $^{\mathrm{b}, \mathrm{c}, \mathrm{f}, \dagger}$ \\ aMolecular and Cellular Pharmacology Graduate Program, Leonard M. Miller School of Medicine, \\ P.O. Box 016189 (R-189), Miami, Florida, USA
}

${ }^{b}$ Center for Cardiovascular and Pulmonary Research at Nationwide Children's Hospital Research Institute, 700 Children's Drive, Columbus, Ohio, 43205, USA

'The Heart Center at Nationwide Children's Hospital, 700 Children's Drive, Columbus, Ohio, 43205, USA

dLaboratory of Connective Tissues Biology, GIGA, University of Liège, Tour de Pathologie, B23/3, B-4000 Sart-Tilman, Belgium

eDevelopmental Biology and Neonatal Medicine Program, Wells Center for Pediatric Research, Indiana University School of Medicine, Indianapolis, Indiana, USA

fDepartment of Pediatrics, The Ohio State University, Columbus, Ohio, USA

\section{Abstract}

Mature heart valves are complex structures consisting of three highly organized extracellular matrix layers primarily composed of collagens, proteoglycans and elastin. Collectively, these diverse matrix components provide all the necessary biomechanical properties for valve function throughout life. In contrast to healthy valves, myxomatous valve disease is the most common cause of mitral valve prolapse in the human population and is characterized by an abnormal abundance of proteoglycans within the valve tri-laminar structure. Despite the clinical significance, the etiology of this phenotype is not known. Scleraxis (Scx) is a basic-helix-loophelix transcription factor that we previously showed to be required for establishing heart valve structure during remodeling stages of valvulogenesis. In this study, we report that remodeling heart valves from $S c x$ null mice express decreased levels of proteoglycans, particularly chondroitin sulfate proteoglycans (CSPGs), while overexpression in embryonic avian valve precursor cells and adult porcine valve interstitial cells increases CSPGs. Using these systems we further identify that $S c x$ is positively regulated by canonical $\operatorname{Tgf} \beta 2$ signaling during this process and this is attenuated by MAPK activity. Finally, we show that Scx is increased in myxomatous valves from human patients and mouse models, and overexpression in human mitral valve interstitial cells modestly increases proteoglycan expression consistent with myxomatous mitral valve phenotypes. Together, these studies identify an important role for Scx in regulating proteoglycans in embryonic and

(C) 2013 Elsevier Ltd. All rights reserved.

${ }^{\dagger}$ Corresponding author: Nationwide Children's Hospital Research Institute, 700 Children's Drive, WB4239, Columbus, OH, 43205, +1-614-722-3330 (fax), +1-614-355-5752 (phone), joy.lincoln@ nationwidechildrens.org.

Publisher's Disclaimer: This is a PDF file of an unedited manuscript that has been accepted for publication. As a service to our customers we are providing this early version of the manuscript. The manuscript will undergo copyediting, typesetting, and review of the resulting proof before it is published in its final citable form. Please note that during the production process errors may be discovered which could affect the content, and all legal disclaimers that apply to the journal pertain.

Disclosures. The authors of this paper have nothing to disclose.

Conflict of Interest. The authors of this paper have no conflicts of interest. 
mature valve cells and suggest that imbalanced regulation could influence myxomatous pathogenesis.

\section{Keywords}

Proteoglycan; Scleraxis; Heart Valve; Myxomatous; Tgf $\beta$; MAPK

\section{Introduction}

The mature mitral valve leaflets are composed of three stratified layers of specialized extracellular matrix (ECM) interspersed with valve interstitial cells (VICs) [1]. The role of the ECM is to provide all the necessary biomechanical properties to withstand constant changes in hemodynamic force during the cardiac cycle. Within the atrioventricular valves, the fibrosa is located furthest away from blood flow and is predominantly comprised of parallel bundles of fibrillar collagens that provide tensile strength. In contrast, elastic fibers within the atrialis layer adjacent to blood flow, allows for flexibility and extensibility. In between these layers is the spongiosa, rich in proteoglycans with a lower abundance of collagens, thereby providing a more compressible matrix. Patterning of the heart valves is initiated during embryonic development and requires extensive remodeling of the endocardial cushions throughout valvulogenesis and into post natal stages [1]. Although the ECM composition of the mature tri-laminar valve has been well described, little is known about the molecular mechanisms that establish and maintain this highly organized structure. This is of clinical significance as alterations in patterning have detrimental effects on valve function and are characteristic of disease.

Mitral valve prolapse affects approximately $5 \%$ of the human population and is characterized by abnormal bulging of the mitral valve leaflets into the left atrium during ventricular systole [2]. Myxomatous degeneration is the most common cause of mitral valve prolapse and the only effective treatment is surgical repair. Histologically, myxomatous valve leaflets are pathologically thickened with alterations in the distribution of ECM components within the tri-laminar connective tissue layers. This includes disrupted collagen fiber organization [3], elastic fiber fragmentation [4] and most prominent, excess accumulation of proteoglycans including Biglycan and Decorin throughout [5-7]. These changes in valve composition weaken the biomechanical properties of the valve resulting in 'floppy' leaflets that fail to coapt, leading to regurgitation. The etiology of mitral valve prolapse is complex and studies have shown linkage to connective tissue disorders and specific mutations in ECM genes (reviewed [1]). Therefore, due to the heritable nature of this disease, it is considered that defects in embryonic valve development could underlie phenotypes observed in the adult population.

Scleraxis (Scx) is a bHLH transcription factor first reported for its expression pattern in developing somites and limb buds [8]. Additional studies in the chick have shown that Scx positively promotes tendon cell fate of mesenchymal precursor cells in these two tissues [913]. Known signaling pathways that regulate Scx are limited, with previous reports describing only Transforming growth factor- $\beta$ (Tgf $\beta$ )-Smad [14] and mitogen-activated protein kinase (MAPK) [15] as upstream regulators in cardiac fibroblasts [14] and developing somites [15], respectively. Mice null for $S c x$ develop severe defects in forcetransmitting and intermuscular tendons associated with reduced and disorganized ECM [16]. This observation is likely attributed to reported roles that Scx plays in regulating tendon progenitor cell differentiation [16] and transcriptional activity of matrix proteins including type Ia 2 collagen (COL1A2) [14, 17]. Our previous work has shown that in developing valves, Scx is expressed at low levels in mesenchyme valve precursor cells of the 
endocardial cushions, however expression is increased during cushion remodeling and trilaminar stratification after birth [18]. Heart valves from $S c x^{-/-}$mice are abnormally thick with defects in valve precursor cell differentiation and ECM organization [18], similar to observations in affected tendons [16]. Together, these studies identify important roles for Scx in regulating the development of connective tissues in structures of high mechanical demand.

In a previous study from our lab we described structural defects associated with loss of ECM stratification in heart valves from $S c x^{-/-}$mice [18]. In this current study we report that valve phenotypes observed in $S c x^{-/-}$mice are largely attributed to a significant decrease in the expression and contribution of chondroitin sulfate proteoglycans (CSPGs) to the mature valve leaflets. To examine the mechanisms of Scx-mediated CSPG regulation, we manipulated Scx function and canonical and non-canonical Tgf $\beta$ signaling pathways in embryonic avian valve precursor cells and mature porcine VICs in vitro. Using these approaches we show that Scx is sufficient to promote CSPG expression in both embryonic and mature valve cells thereby promoting a molecular profile similar that observed in myxomatous mitral valve disease. In addition, $S c x$ is increased in VICs and mitral valves isolated from human patients and mouse models of myxomatous disease. We further delineate that $S c x$-mediated regulation of CSPGs is positively regulated upstream by canonical Tgf $\beta$-Smad signaling, while activated MAPK attenuates this pathway in a Tgf $\beta$ independent manner. Findings from this study provide new mechanistic insights into the role of Scx in the regulation of CSPGs in heart healthy valve leaflets and raises interest for Scx function in the pathogenesis of myxomatous valve disease.

\section{Materials and Methods}

\subsection{Mouse tissue collection}

$S c x^{-/-}$and $S c x^{+/+}$littermate mice were generated as previously described $[16,18]$, and collected at embryonic (E) day 16.5, counting day E0.5 by evidence of a copulation plug. For histology, hearts were dissected in $1 \mathrm{X}$ phosphate-buffered saline (PBS) and fixed in $4 \%$ paraformaldehyde (PFA)/PBS overnight at $4{ }^{\circ} \mathrm{C}$. After fixation, hearts were processed for paraffin wax embedding and sectioned at $8 \mu \mathrm{m}$ for immunohistochemistry [18]. Alternatively, atrioventricular canal (AVC) tissue was dissected from unfixed hearts at

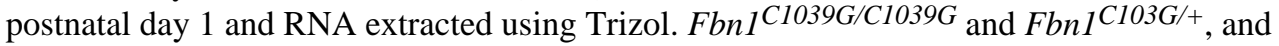
$\mathrm{FbnI}^{+/+}$(wild type) mice were generated as described [19], and RNA isolated from AVC tissue dissected from hearts at postnatal day 6.5. $\operatorname{Tgf} \beta 2^{-/-}, \operatorname{Tgf} \beta 2^{-/+}$, and $\operatorname{Tgf} \beta 2^{+/+}$mice were generated and genotyped as described [20], and RNA was extracted from whole hearts at E13.5. All animal procedures were approved and performed in accordance with The Nationwide Children's Hospital Research Institute IACUC guidelines.

\subsection{Heart Valve Explant Cultures}

Mitral and tricuspid valves were dissected from hearts of $S c x^{+/-}$, and $S c x^{+/+}$(wild type) mice at postnatal day 1 and cultured as explants on pore filters as previously described [21]. At the time of culture, BSA or $200 \mathrm{pM}$ Tgf $\beta 2$ was added to the growth media [22] and explants were cultured for a further 48 hours. Following treatment, RNA was collected using standard Trizol protocols.

\subsection{Generation of adenovirus}

Full length mouse Scx was amplified from E14.5 mouse limb genomic DNA using PCR designed to add FLAG at the 5' end: 5'-C TGG ATC CGC CAC CATG GAC TAC AAG GAC GAC GAT GAC AAA TCC TCC GCC ATG CTG CGT TCA G and 3'-CGT GAA TTC TCA ACT TCG AAT CGC CGT CTT TCT G. The underlined sequence encodes the 
FLAG (DYKDDDDK) tag. Scx-FLAG was cloned into the pShuttle-IRES-hrGFP-1 vector and adenoviral Scx-FLAG (AdV-Scx-FLAG) was produced and tittered using the AdEasy$\mathrm{XL}$ and AdEasy Viral Titer kits according to manufacturer's instructions (Stratagene).

\subsection{Endocardial cushion chicken valve precursor cell cultures}

Fertilized White Leghorn chicken eggs (Charles River Laboratories) were incubated in high humidity at $38^{\circ} \mathrm{C}$, and embryonic hearts were collected at Hamburger Hamilton (HH) stage 25. Atrioventricular endocardial cushions were dissected away from the adjacent myocardium and cultured as described [22]. Following 72 hours of culture, valve precursor cells were infected with $1.5 \times 10^{9}$ PFU AdV-GFP, $3.5 \times 10^{7}$ PFU constitutively active MEK1 (AdV-caMEK1), or $8.5 \times 10^{8} \mathrm{PFU}$ dominant negative MEK1 (AdV-dnMEK1) in serum-free media for a time-course of 4, 16, and 48 hours. Adenoviruses were obtained from Dr. Jeff Molkentin, Cincinnati Children's Hospital Medical Center (Seven Hills Bioreagents) [23, 24]. For Scx gain-of-function studies, cultures were infected for 48 hours with AdV-ScxFLAG or AdV-GFP control. For growth factor studies, cultures were treated with 200pM Tgfß2 (Sigma) or BSA vehicle control for 30 minutes and 48 hours in normal growth media. Following treatment, protein and RNA were collected using standard protocols (see below), or cells were fixed in 4\% PFA for 30 minutes at room temperature.

\subsection{Murine $\mathrm{C}_{3} \mathrm{H}_{10 \mathrm{~T}} \mathrm{~T}_{1 / 2}$ and NIH3T3 cell cultures}

$\mathrm{C}_{3} \mathrm{H}_{10 \mathrm{~T}_{1 / 2}}$ and NIH3T3 cells were obtained from the American Type Culture Collection and maintained in growth media as recommended. $70 \%$ confluent cultures were treated with $200 \mathrm{pM}$ Tgf $\beta 2$ or BSA vehicle control for 48 hours in normal growth media. For MEK rescue studies, $\mathrm{C} 3 \mathrm{H} 10 \mathrm{~T} 1_{12}$ cell cultures were pre-treated with AdV-caMEK1, AdVdnMEK1, or AdV-GFP for 6 hours in serum-free media (as above). Following infection, media was removed and replaced with normal growth media supplemented with $200 \mathrm{pM}$ Tgf 32 or BSA vehicle control for 48 hours. After treatments, RNA and was collected using standard protocols, or cells were fixed in 4\% PFA for 30 minutes at room temperature (see details below).

\subsection{Human mitral valve interstitial cell (hMVIC) cultures}

Mitral valve tissue was collected from four control patients rejected for transplantation and three myxomatous mitral valve prolapse (MMVP) patients during elective surgery. Human mitral VIC cultures were established and maintained in serum-supplemented EBM media as described [25]. Cells were passaged to P7 and used for in vitro studies. Control cells were seeded in 6-well plates to $\sim 70 \%$ confluency and infected with $4 \times 10^{8}$ PFU AdV-GFP (Seven Hills Bioreagents) or $1.6 \times 10^{7}$ PFUAdV-Scx-FLAG. The differences in these PFU values are based upon the consistent infection efficiencies of 76.17\% $\pm 4.12 \%$ (AdV-GFP) and 78.27\% $\pm 2.67 \%$ (AdV-Scx). 48 hours post-infection, RNA was collected using standard protocols (see below). Additionally, untreated human MVICs from control and MMVP patients were plated for 48 hours and RNA was isolated using Trizol.

\subsection{Porcine valve interstitial cell cultures}

Porcine valve interstitial cells were isolated as previously described [26] and plated on collagen-coated chamber slides to $\sim 80 \%$ confluency. Cultures were infected with AdV-GFP or AdV-Scx-FLAG in serum-free media, or 200pM Tgf $\beta 2$ or BSA vehicle control in normal growth media for 48 hours. Following treatment, cultures were fixed with 4\% PFA for 30 minutes at room temperature and subjected to immunohistochemistry (see below). 


\subsection{RNA isolation, cDNA synthesis, and quantitative PCR}

mRNA was isolated using Trizol (Invitrogen) as previously described [27] and cDNA was generated from 200-300ng mRNA using high capacity RNA-to-DNA kit according to manufacturer's instructions (Applied Biosystems). $1 \mu \mathrm{l}$ cDNA was subject to quantitative PCR amplification (StepOne Plus, Applied Biosystems) using specific primers targeting chicken, mouse, and human mRNAs listed below. In addition, Taqman probes (Applied Biosystems) were used to target human, murine, and chicken $S c x$. Following PCR analyses, the cycle count threshold $(\mathrm{Ct})$ was normalized to species specific housekeeping genes (GAPDH chicken, $L 7$ mouse, and $18 S$ human) and the $\triangle \mathrm{Ct}$ and fold changes in experimental samples over controls was determined [27]. Statistically significant differences in gene expression levels were determined using Student's t-test or one-way ANOVA plus a posthoc test as indicated in the figure legend, on at least 3 independent experiments with $p<0.05$ considered significant.

PCR primer sequences

\begin{tabular}{|c|c|c|}
\hline \multirow{2}{*}{$\frac{\text { Gene }}{\text { Perlecan }}$} & \multicolumn{2}{|c|}{ Sequence (5' to 3 ') } \\
\hline & Mouse: & F-5'-GCTGCTAGCGGTGACGCATGG-3' \\
\hline & & R: 5'-ACTGTGCCCAGGCGTCGGAA-3' \\
\hline \multirow[t]{2}{*}{ Lumican } & Mouse: & F: 5'-CTGACCGAGTCCGTCGGTCCA-3' \\
\hline & & R: 5'-CCGTCGAAGGAGCCGAGCTT-3' \\
\hline \multirow[t]{2}{*}{ Brevican } & Mouse: & F: 5'-CGACAGTGCCAGCCACGGTG-3' \\
\hline & & R: 5'-GCCTGGCAAACATAGGCAGCGG-3' \\
\hline \multirow[t]{2}{*}{ Neurocan } & Mouse: & F: 5'-CGGCCTGAATGACCGGACAGTAGA3' \\
\hline & & R: 5'-CGCCCACTCTCATGTGCCACC-3' \\
\hline \multirow[t]{6}{*}{ Decorin } & Chicken: & F: 5'-GCCACGCGGTTCCACCAGAA-3' \\
\hline & & R: 5'-CAGCGGAAGGGGCACACTGG-3' \\
\hline & Mouse: & F: 5'-GGTGTCAGCTGGATGCGCTCAC \\
\hline & & R: 5'-TGCAGCCCAGGCAAAAGGGTT-3' \\
\hline & Human: & F: 5'-CTGGGCTGGACCG TTTCAAC-3' \\
\hline & & R: 5'-GATGGCATTGACAGCGGAAGG-3' \\
\hline \multirow[t]{4}{*}{ Biglycan } & Mouse: & F: 5'-TTACTGACCGCCTGGCCATCCA-3' \\
\hline & & R: 5'-TGCTTAGGAGTCAGGGGGAAGCTGT-3' \\
\hline & Human: & F: 5'-ACACCATCAACCGCCAGAGTC-3' \\
\hline & & R: 5'-GACAGCCACCGACCTCAGAAG-3' \\
\hline \multirow[t]{4}{*}{ Aggrecan } & Mouse: & F: 5'-GCTGCCCCTGCCCCGTAATG-3' \\
\hline & & R: 5'-AGTCCGGCCCACGTGTGACT-3' \\
\hline & Human: & F: 5'-TGCGTGGGTGACAAGGACAG-3' \\
\hline & & R: 5'-CAAGGCGTGTGGCGAAGAAC-3' \\
\hline \multirow[t]{4}{*}{ Fibromodulin } & Mouse: & F: 5'-CTGCCACATTCTCCAACCCAAGG \\
\hline & & R: 5'-AGGACGGAGGCCCACTGCATT-3' \\
\hline & Human: & F: 5'-GGCTGCTCTGGATTGCTCTC-3' \\
\hline & & R: 5'-CGGGTCAGGTTGTTGTGGTC-3' \\
\hline \multirow[t]{3}{*}{ Versican } & Chicken: & F: 5'-CGGCTGAGAGAGAATGCCGCC \\
\hline & & R: 5'-TCCGGCTGGTTTGGTCGCCA-3' \\
\hline & Mouse: & F: 5'-GCTGCCCCGAGCCTTTCTGG \\
\hline
\end{tabular}

J Mol Cell Cardiol. Author manuscript; available in PMC 2014 December 01. 


\begin{tabular}{|c|c|c|}
\hline \multirow[t]{2}{*}{ Gene } & \multicolumn{2}{|c|}{ Sequence (5' to 3 ') } \\
\hline & & R: 5'-GCGCTTGGCCACAGCACCTC-3' \\
\hline & Human: & F: 5'-ATCTGGATGGTGATGTGTTC-3' \\
\hline & & R: 5'AATCGCACTGGTCAAAGC-3' \\
\hline \multirow[t]{2}{*}{ Collagen Ia2 } & Human: & F: 5'-CGTGGCAGTGATGGAAGTGTG-3' \\
\hline & & R: 5'-ACCAGCAGGACCAGCGTTAC-3' \\
\hline \multirow[t]{2}{*}{ Collagen IIaI } & Human: & F: 5'-TGGAGCAGCAAGAGCAAGGAG-3, \\
\hline & & R: 5'-CGTGGACAGCAGGCGTAGG-3' \\
\hline \multirow[t]{2}{*}{$18 S$} & Human: & F: 5'-AACGATGCCAACTGGTGATGC-3' \\
\hline & & R: 5'-CTCCTGGTGGTGCCCTTCC-3' \\
\hline
\end{tabular}

\subsection{Western blotting}

Avian valve precursor and $\mathrm{C}_{3} \mathrm{H}_{10 \mathrm{~T}_{1 / 2}}$ cells were lysed in sample buffer (1X SDS buffer,

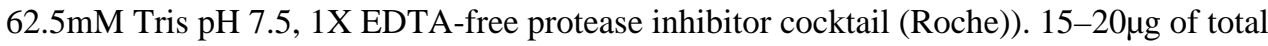
protein for each experimental sample was run on $12 \%$ Tris-Glycine SDS PAGE gel (BioRad) and transferred to $0.45 \mu \mathrm{m}$ nitrocellulose membranes (BioRad) at $300 \mathrm{~mA}$ for 1.5 hrs. Membranes were blocked in 3\% bovine serum albumin (BSA, Millipore) for $1 \mathrm{hr}$ and probed with antibodies against CS-56 (CSPG) $\left(1: 1000,4^{\circ} \mathrm{C}\right.$ overnight, Sigma), Actin/ Tubulin (1:5000, $1 \mathrm{hr}$ room temperature, Chemicon/Millipore), di-phospho-ERK1/2 Thr202/ Tyr204 (dpERK1/2) $\left(1: 1000,4^{\circ} \mathrm{C}\right.$ overnight, Cell Signaling), or phospho-Smad2 (pSmad $465 / 467)\left(1: 1000,4^{\circ} \mathrm{C}\right.$ overnight, Cell Signaling in $1.5 \%$ BSA, followed by incubation with anti-mouse- or anti-rabbit-horseradish peroxidase-conjugated secondary antibody (1:15000, $1 \mathrm{hr}$ room temperature, Cell Signaling). Membranes were then washed three times in $1 \mathrm{x}$ TBST for 10 minutes and developed using Super Signal West Femto Substrate (Pierce) and BioMax MR film (Eastman Kodak). Band densities were calculated from at least 3 biological replicates and normalized to loading controls using Image Pro Plus software.

\subsection{Immunofluorescence}

Fixed avian valve precursor, porcine aortic valve interstitial, and $\mathrm{C}_{3} \mathrm{H}_{10} \mathrm{~T} \mathrm{~T}_{1 / 2}$ cell cultures were washed twice in 1X PBS and blocked (2\% horse serum, 2\%BSA, 0.1\% NP-40/PBS) for $1 \mathrm{hr}$ at room temperature. CS-56 antibody to detect CSPG expression was diluted (1:200, Sigma) in 1:1 blocking solution/PBS, and cells were incubated for $4^{\circ} \mathrm{C}$ overnight. Cells were washed 3 times in 1X PBS and incubated with Alexa anti-mouse-568 secondary antibody (1:400, $1 \mathrm{mg} / \mathrm{ml}$, Molecular Probes) for $1 \mathrm{hr}$ at room temperature. Cells were then washed, stained with DAPI for 10 mins at room temperature and mounted in Vectorshield (VectorLabs). Fluorescent immunoreactivity was visualized using Olympus BX60 microscope, and captured using CellSens imaging software. Immunoreactivity was quantitated using Image Pro Plus software and calculated as the intensity sum of Alexa-568 positive CSPGs, over the total number of DAPI-positive stained nuclei.

\section{Results}

\subsection{Proteoglycan expression is attenuated in heart valves from embryonic and post natal} Scx ${ }^{-1-}$ mice

We have previously shown that $S c x^{-1-}$ mice develop valve phenotypes associated with alterations in connective tissue organization [18]. As proteoglycans are highly abundant within valves particularly within the spongiosa, we examined if expression was affected in Scx null mice using a combination of qPCR and immunohistochemistry (IHC). In 
atrioventricular canal regions from post natal $\mathrm{Scx}^{-/-}$mice, expression of keratin sulfates (lumican, fibromodulin) and chondroitin sulfate proteoglycans (CSPG) (brevican, neurocan, decorin, biglycan) were all significantly downregulated compared to wild type $\left(S_{C x}{ }^{+/+}\right)$ controls. No significant changes were observed in perlecan (heparin sulfate proteoglycan), aggrecan or versican (CSPGs) (Figure 1A). Additional IHC analysis using a pan-CSPG antibody revealed decreased and punctate expression patterns of CSPGs within remodeling mitral valve leaflets of post natal $S c x^{-/-}$pups (Figures $1 \mathrm{~B}-\mathrm{C}$ ). Similar findings were observed in $\mathrm{Scx}^{-/}$mice at E15.5 and 3 months of age (data not shown). Normal extracellular CSPG immunoreactivity was observed in regions where Scx is not normally expressed (atria shown in Figure 1D-E). These analyses suggest that Scx is important for expression of proteoglycans in developing heart valves.

\subsection{Scx overexpression in embryonic heart valve precursor cells and adult valve interstitial cells leads to increased CSPG expression}

Our in vivo data shows that loss of $S c x$ leads to decreased expression of proteoglycans, including CSPGs (Figure 1). To determine if Scx gain of function is sufficient to promote CSPG expression, we utilized established embryonic avian valve precursor and adult porcine valve interstitial cell in vitro systems [22, 28]. In the avian system, atrioventricular endocardial cushions are isolated away from the adjacent myocardium of HH Stage 25 chick embryos, and mesenchyme valve precursor cells within the cushions are cultured as a monolayer in the absence of cell-cell contact. At this stage, the valve precursor cells do not express high levels of Scx and are considered undifferentiated [22]. In the porcine model, valve cells are isolated from juvenille pigs and are therefore considered mature myofibroblast-like interstitial cells. Using these embryonic and adult valve cells model systems, we overexpressed Scx by infecting with a GFP-labeled adenovirus containing full length FLAG-tagged mouse Scx cDNA (AdV-Scx-FLAG) for 48 hours. As a control, cells were infected with empty GFP-labeled adenovirus (AdV-GFP). Consistent with our loss of function studies, gain of function in vitro leads to increased CSPG expression as observed by Western blot analysis of CSPG expression in avian valve precursor cells (Figure 2A-B) and immunostaining in porcine valve interstitial cells (VICs) (Figure 2C-E). These studies suggest that in both embryonic and mature valve cells Scx is sufficient to promote CSPG expression in vitro.

\subsection{Scx and CSPG expression is positively regulated by $\operatorname{Tgf} \beta 2$}

Previous studies have shown that $S c x$ is positively regulated by $\operatorname{Tgf} \beta$ signaling in fibroblasts and tenocytes [14, 17, 29-31]. However conserved mechanisms in the valve have not been reported. To address this, avian valve precursor cells were treated with 200pM Tgf $\beta 2$ for 48 hours and $S c x$ expression was examined. As shown in Figure 3A, $S c x$ is increased 1.7-fold $( \pm 0.14)$ in treated valve precursor cells, and this pattern was also observed in similarly treated murine mesenchymal $\mathrm{C}_{3} \mathrm{H}_{10 \mathrm{~T}_{1 / 2}}(54.3$-fold \pm 2.96$)$ and mouse fibroblast NIH3T3 (8.2-fold \pm 1.21 ) cell lines. In support of the positive regulation of $S c x$ by Tgf $\beta 2$, qPCR analysis shows decreased $S c x$ mRNA levels in hearts isolated from E13.5 Tgf $\beta 2^{+/-}$and $T g f \beta$ $2^{-/-}$mice (Figure 3B). To further determine if Tgf 32 -mediated $S c x$ expression promotes CSPG expression, immunostaining was performed in treated avian valve precursor cells (Figure 3C, D, G) and porcine VICs (Figure 3E, F, H). Consistent with Scx overexpression studies (Figure 2), Tgf $\beta 2$ is sufficient to promote CSPG expression in embryonic and mature valve cells. Mitral valve explants from PND1 $S c x^{+/+}$and $S c x^{+/-}$mice were also subjected Tgf $\beta 2$ treatment to examine the requirement of $S c x$ for Tgf $\beta 2$-mediated regulation of CSPGs. Of the CSPGs examined (decorin, lumican, versican, biglycan), only aggrecan expression was significantly increased in response to $\operatorname{Tgf} \beta 2$ treatment and this was not observed in $S c x^{+/-}$treated explants (Figure 3I). Together, these data show that Tgf $\beta$ - 
mediated regulation of $S c x$ is conserved in heart valves, and this pathway is sufficient to promote CSPG expression.

\subsection{MAPK signaling attenuates Tgf $\beta 2$-mediated $S c x$ regulation}

Studies have shown that $\operatorname{Tgf} \beta$ treatment of myofibroblasts is mediated through canonical Smad(2) signaling, and Smad3 functionally interacts with Scx to regulate activity of target genes including COL1A2 [14, 17]. In this study we show that Tgf $\beta 2$ treatment of avian valve precursor cells similarly increases pSmad2 expression after 30 minutes (Figure 4A). In addition to Smads we, and others have shown that Scx can also be regulated by MAPK signaling in valve precursor cells and developing somites [15, 22, 32]. As Tgf $\beta$ can signal through non-canonical MAPK pathways, we examined expression levels of di-phospho ERK1/2 Thr202/Tyr204 (dpERK1/2) as an indicator of MAPK activity. By Western blot, significant changes in dpERK1/2 expression were not observed following Tgf $\beta 2$ treatment, further suggesting that Smad is the downstream effector of Tgf $\beta 2$ signaling in the regulation of $\mathrm{Scx}$ in this system. However, when $\mathrm{C}_{3} \mathrm{H}_{10 \mathrm{~T}_{1 / 2}}$ cells were co-treated with an adenovirus of constitutively active MEK1 (AdV-caMEK1) [24] a known downstream effector of ERK1/2 for 6 hours prior to Tgf $\beta 2$ treatment, $S c x$ expression was significantly attenuated compared to Tgf $\beta 2$ treatment alone (Figure 4B). Similar co-treatment with a dominant negative MEK1 (dnMEK1) adenovirus (AdV-dnMEK1) [23] for 6 hours had no effect on the ability of $\mathrm{Tgf} \beta 2$ to promote $S c x$. $\mathrm{C}_{3} \mathrm{H}_{10 \mathrm{~T}_{1 / 2}}$ cells were chosen for these studies as they exhibit embryonic mesenchymal cell phenotypes similar to valve precursor cells [33]. It therefore appears that Tgf $\beta 2$-Smad signaling positively regulates $S c x$ expression, and Tgf $\beta 2$ independent MAPK activity can repress this pathway.

\subsection{MAPK signaling negatively regulates Scx in heart valve precursor cells}

Our data shows that MAPK signaling represses Tgf $\beta 2$-mediated regulation of $S c x$. To examine if MAPK activity regulates $S c x$ in the absence of exogenous Tgf $\beta 2$, avian valve precursor cells were subject to infection with AdV-caMEK1 and AdV-dnMEK1 for 48 hours. As confirmed by Western blot, 48 hour AdV-caMEK1 and AdV-dnMEK1 treatments successfully increased and decreased dpERK1/2 respectively in valve precursor cells (Figure 5A). Only one band was observed when detecting dpERK1/2 Thr202/Tyr204, consistent with previous reports using the same avian valve precursor cell culture system [34]. To determine if altered MEK1 (and therefore ERK1) activity effects $S c x$ expression in valve precursor cells, a time course of AdV-caMEK1 and AdV-dnMEK1 treatments were performed. At 48 hours post infection, significant increases in $S c x$ expression were observed with AdV-dnMEK1 treatment, while in contrast $S c x$ was decreased following AdV-caMEK1 infection (Figure 5B). In addition to changes in Scx expression, AdV-caMEK1 treatments reduced CSPG expression, while AdV-dnMEK1 infections increased levels as determined by Western blot (Figure 5C-D) and immunohistochemistry (Figure 5E-G) analysis. Collectively, these data suggest that in heart valve precursor cells, MAPK signaling negatively regulates $S c x$ and CSPG expression, even in the absence of active endogenous Tgf $\beta$ signaling.

\subsection{Overexpression of Scx in mature human valve interstitial cells promotes proteoglycans}

We have shown that Scx overexpression in avian valve precursor cells and porcine VICs promotes expression of CSPGs (Figure 2). To further extend this using a more clinically relevant model system, we infected human mitral VICs isolated from donor hearts [25] with AdV-Scx, and examined levels of several proteoglycans and collagens abundantly expressed in human myxomatous mitral valve disease. As expected with human samples, we observed variability in gene expression fold changes by qPCR across the four independent nondiseased samples. However, analysis showed a consistent trend towards increased 
expression of aggrecan, biglycan, decorin, fibromodulin, type I and II collagen and versican in AdV-Scx-FLAG infected samples compared to AdV-GFP controls (Table 1). This data shows that Scx gain of function can promote molecular phenotypes associated with myxomatous valve disease in otherwise healthy human VICs.

\subsection{Scx is increased in myxomatous mitral valves from human patients and mouse models}

Mice carrying a homozygous or heterozygous knock in mutation for Fibrillin-1 $\left(\mathrm{Fbn1} \mathrm{C}^{\mathrm{ClO} 39 \mathrm{G}}\right.$ ) serve as a model for Marfan Syndrome and develop myxomatous changes in mitral valves by post natal day (PND) 6.5 [19]. To determine if $S c x$ expression is altered in this established model of myxomatous disease, qPCR was performed on atrioventricular canal regions isolated from $\mathrm{Fbnl} \mathrm{ClO39G}^{\mathrm{C} 1039 \mathrm{G}}$ and $\mathrm{Fbnl} \mathrm{ClO39G/+}$ mice. As shown in Figure 6A, Scx expression is significantly increased in $\mathrm{Fbn1} \mathrm{ClO39G}^{\mathrm{CC} 1039 \mathrm{G}}$ mice at PND6. In addition to mice, increased $S c x$ expression was also observed in mitral VICs isolated from two, out of three human patients [25] (Figure 6B). Together, this highlights the potential pathophysiological impact of this study and suggests that Scx could play an important role in mediating myxomatous mitral valve disease pathogenesis.

\section{Discussion}

The molecular mechanisms responsible for the regulation of the bHLH transcription factor Scx, and associated downstream target genes during heart valve development remain unknown. Here, we demonstrate that Scx is both necessary and sufficient for expression of proteoglycans associated with the spongiosa layer, including CSPGs, in both embryonic and mature valve cells. Similarly, Scx can promote a trend towards increased expression of proteoglycans and collagens in VICs isolated from human mitral valves, thereby promoting myxomatous mitral valve disease-like phenotypes. Dissection of molecular pathways previously shown to regulate $S c x$ in other systems reveals that $S c x$ is regulated upstream by canonical Tgf $\beta$ signaling to promote CSPG expression. Further, we show that activated MAPK attenuates Tgf $\beta 2$-mediated $S c x$ expression, and represses $S c x$ mRNA and CSPGs in the absence of Tgf $\beta 2$. Overall, these data support a positive role for Tgfß-Smad as a regulator of $S c x$ and proteoglycan expression in embryonic and adult valve structures, and demonstrate modulation of this pathway by MAPK. Further, we have identified a signaling pathway that when altered, could underlie myxomatous mitral valve pathogenesis observed in the human population.

It is well described that an abnormal abundance of proteoglycans, including CSPGs are a histological hallmark of myxomatous valve disease, however mechanisms that establish and maintain proteoglycan homeostasis in healthy developing and mature valve structures have not been described. In this study we identify the bHLH transcription factor Scx as a regulator of CSPG expression in immature valve precursor cells and mature valve interstitial cells (Figures 1 and 2). In vitro, this is mediated upstream by Tgf 32 -Smad signaling (Figures 2 and 3 ) and although this has not been examined in vivo, $\operatorname{Tgf} \beta 2$ (and $\operatorname{Tgf} \beta 3$ ) is highly expressed in VICs from early remodeling stages [35] consistent with Scx [18]. However, Tgf $\beta 1$ is also sufficient to promote $S c x$ in muscle and cardiac fibroblasts [14, 17, 29-31] and therefore as a secretory growth factor, it is plausible that $\mathrm{Tgf} \beta 1$ from surrounding valve endothelial cells [35] could act upon Scx in VICs in vivo. Consistent with Tgf $\beta 1$ as a positive regulator of $S c x$, we show that $S c x$ is reduced in hearts from $T g f \beta 2^{-/-}$mice (Figure 3B). Interestingly, $\operatorname{Tg} f \beta 2^{-/-}$mice have valve remodeling defects associated with leaflet thickening and increased proteoglycan deposition by E18.5 [20]; contradictory to findings presented from this study (Figure 3). However, VIC proliferation is increased in $T g f \beta 2^{-l-}$ mice from as early as E14.5, and therefore it is possible that the over abundance of proteoglycans is secondary to increased cell number, and independent of reduced, but not 
absent Scx expression (Figure 3B). Our data shows that CSPGs brevican, neurocan, decorin, biglycan and not aggrecan are significantly reduced in valves from $\mathrm{Scx}^{-/-}$mice (Figure 1). However only aggrecan is significantly increased in response to Tgf $\beta 2$ treatment of post natal mitral valve explants (Figure 2) consistent with previous tendon studies [36]. Therefore it is considered that similar to previous findings in tendons and cardiac fibroblasts, $[14,17$, 29-31] other Tgf $\beta$ ligands may play a role in regulating Scx-mediated CSPG expression in the valves.

Studies have shown that formation of highly organized valve structures is dependent on the tight regulation of signaling pathways in a temporal and spatial manner [1]. In this study we have not only identified that Tgf $\beta 2$-Smad signaling positively regulates $S c x$ and CSPG expression (Figure 3), but show that MAPK signaling converges onto this pathway to have a negative effect (Figures 4 and Figure 5). As Tgf $\beta 2$ treatment does not affect ERK activity (Figure 4A), and MEK1 regulates $S c x$ in the absence of Tgf $\beta 2$ treatment (Figure 4B), it is likely that MAPK can function as a repressor of $S c x$ in a Tgf $\beta 2$-independent manner. Our findings show that direct activation of dpERK1/2 negatively regulates $S c x$, while reduced dpERK1/2 activity increases $S c x$ (Figure 5B). In mesenchymal precursor cells of the developing somites, the opposite is observed; active dpERK is crucial for $S c x$ expression [15], however, increased activity also induces expression of the dual specificity phosphatase $M k p 3$. Thereby introducing a negative feedback loop to appropriately downregulate ERKinduced $S c x$ activation to restrict its expression during precursor cell specification and differentiation [15]. In contrast to somites, increased $S c x$ was not observed in valve precursor cells at 4,16 or 48 hours following AdV-caMEK1 infection (Figure 5A), and therefore we are doubtful that similar feedback mechanisms are conserved within these two precursor cell populations. However, it cannot be excluded that phosphatase activity is important for modulating dpERK1/2 activity in valves in order to regulate appropriate levels of $S c x$ and establish formation of the proteoglycan-rich spongiosa layer.

Findings in Figure 5 suggest that direct manipulation of MEK1 suppresses $S c x$ in the absence of exogenous Tgf $\beta 2$ signaling, however there are several pieces of data to suggest that $\mathrm{pERK} 1 / 2$ as a kinase does not directly regulate $S c x$ expression through protein phosphorylation events. First, manipulation of MEK1/2 lead to changes in Scx at the transcript level. Second, prediction software did not reveal ERK1/2 phosphorylation sites within the Scx sequence, and third, decreased Scx expression was not observed until 48 hours after Adv-caMEK1/2 treatment, which is longer than anticipated for a phosphorylation event. It was therefore considered that pERK1/2 could positively regulate a repressor, or negatively regulate an activator of $S c x$ in a signaling cascade independent of Tgf $\beta$ activity. However, our data in Figure 4B also suggests that ERK1/2 attenuates Tgf $\beta 2$-Smad-mediated activation of $S c x$ and therefore when Tgf $\beta$ signaling is active, ERK1/2 converges onto this signaling pathway. While it remains unclear how this occurs, crosstalk between MAPK and Smad has been reported in Xenopus [37] and murine cell lines [38] through ERK-mediated phosphorylation of the Smad linker region that has been shown to both suppress [37] and increase [38] transcriptional activation of downstream target genes.

While direct target genes regulated by Scx in heart valves remain unknown, Scx has previously been shown to regulate ECM matrix proteins in other systems. In developing chick limbs, Scx gain of function promotes Tenascin and Tendomodulin; two glycoproteins highly expressed in tendons $[9,13,39]$. Although these studies have been informative in identifying genes that change in response to $S c x$ function, direct regulation was not been reported. More recently, Czubryt and colleagues demonstrated molecular interactions and transactivation of Scx with E-box sites within the proximal promoter region of COL1A2 in cardiac fibroblasts [17]. This study also showed that Scx-mediated regulation of COL1A2 is induced by TGF $\beta 1$ signaling, and dependent on Smad3 [17]. The mechanism(s) of how Scx 
regulates proteoglycans in heart valve precursor and interstitial cells as shown in this current study is not yet clear. It is suggested that similar to COL1A2, Scx regulates specific proteoglycan genes (Figure 1A)) through identified conserved E-box binding sites. Scx may not regulate the transactivation of CSPGs alone, but form multi/hetero dimers with known bHLH co-regulators including E2A proteins E12 and E47 [14, 17].

Formation of the stratified valve structures begins in the embryo with localized secretion of collagens, proteoglycans and elastin by valve precursor cells within the developing trilaminar layers. Perturbations in this process either during development, or after birth can lead to alterations in ECM distribution, improper valve biomechanics and valve dysfunction. In myxomatous valve disease, changes in ECM abundance are associated with an abnormal increase in proteoglycans [7] and this is commonly observed in patients with Marfan's syndrome. In mice null for Scx, ECM organization is perturbed and valves are significantly thickened from as early as E16.5 [18]. However, as shown in Figure 1, proteoglycans are reduced and cell number is lower in $S c x^{-1-}$ embryos. Therefore, we speculate that thickening is the result of observed collagen fiber fragmentation and increased collagen deposition [18] that may be reflective of a fibrotic valvulopathy.

Genetic causes of Marfan syndrome (fibrillin-1 (fbn1) mutations) and the Marfan's syndrome-like condition, Loeys-Dietz syndrome (TGF $\beta$ receptor $1 / 2$ mutations) result in increase TGF $\beta$ signaling [40, 41]. Affected $F b n I^{C 1039 G}$ mice (and humans [42]) show significant increases in Tgf $\beta$ signaling and treatment with neutralizing antibodies during stages of embryonic endocardial cushion remodeling (E14.5-E17.5) rescues mitral valve defects [19]. Therefore suggesting that increased Tgf $\beta$ signaling underlies disease pathogenesis, and myxomatous mitral valve disease has origins during valvulogenesis and in particular stages of cushion remodeling. Interestingly, both Smad2/3 and Erk1/2 are increased in $\mathrm{Fbnl}{ }^{\mathrm{ClO} 9 \mathrm{G}}$ mice and Marfan syndrome patients due to the paradoxical activation of TGF $\beta$ signaling [43]. In this study we observed only a subtle, but significant decreased in $S c x$ expression ( $30 \%$ ) in E13.5 hearts from $T g f \beta 2^{+/-}$and $T g f \beta 2^{-/-}$mice (Figure 3). This could be attributed to compensation by other Tgf $\beta$ ligands, but could also be the result of an imbalance in the regulation of $S c x$ by Erk1/2 and Smad2/3.

The role of Scx in myxomatous mitral valve disease has not been reported, yet this study shows that $S c x$ is regulated by $\operatorname{Tgf} \beta 2$ and promotes proteoglycans in valve cells including those from human subjects (Table 1); therefore recapitulating observations made in valves surgically removed from myxomatous mitral valve disease patients at the time of replacement surgery [7, 44] [4]. Mutations in Scx have not been described in the human population, however our work (this study, [18]) shows $t$ hat Scx function must be tightly regulated in order to establish and maintain the matrix components that form the tri-laminar valve structure. Further, our work has identified a novel target of Tgf $\beta$ signaling that could mediate myxomatous changes in heart valve structures.

\section{Acknowledgments}

We thank Blair Austin, Harriet Hammond and Agata Levay for technical assistance, as well as Dr. Jeff Molkentin for adenoviral reagents. This work is supported by NHLBI R01HL091878, R01HL091878-s1 (JL), American Heart Association Predoctoral Fellowship 13PRE16270014 (DNB) and The Research Institute at Nationwide Children's Hospital.

\section{References}

1. Lincoln J, Yutzey KE. Molecular and developmental mechanisms of congenital heart valve disease. Birth defects research Part A, Clinical and molecular teratology. 2011; 91:526-534.

2. Guy TS, Hill AC. Mitral valve prolapse. Annual review of medicine. 2012; 63:277-292. 
3. Nasuti JF, Zhang PJ, Feldman MD, Pasha T, Khurana JS, Gorman JH 3rd, et al. Fibrillin and other matrix proteins in mitral valve prolapse syndrome. The Annals of thoracic surgery. 2004; 77:532536. [PubMed: 14759433]

4. Akhtar S, Meek KM, James V. Ultrastructure abnormalities in proteoglycans, collagen fibrils, and elastic fibers in normal and myxomatous mitral valve chordae tendineae. Cardiovascular pathology: the official journal of the Society for Cardiovascular Pathology. 1999; 8:191-201. [PubMed: 10724523]

5. Olsen EG, Al-Rufaie HK. The floppy mitral valve. Study on pathogenesis. British heart journal. 1980; 44:674-683. [PubMed: 7459151]

6. Kinsella MG, Bressler SL, Wight TN. The regulated synthesis of versican, decorin, and biglycan: extracellular matrix proteoglycans that influence cellular phenotype. Critical reviews in eukaryotic gene expression. 2004; 14:203-234. [PubMed: 15248816]

7. Gupta V, Barzilla JE, Mendez JS, Stephens EH, Lee EL, Collard CD, et al. Abundance and location of proteoglycans and hyaluronan within normal and myxomatous mitral valves. Cardiovascular pathology : the official journal of the Society for Cardiovascular Pathology. 2009; 18:191-197. [PubMed: 18621549]

8. Cserjesi P, Brown D, Ligon KL, Lyons GE, Copeland NG, Gilbert DJ, et al. Scleraxis: a basic helixloop-helix protein that prefigures skeletal formation during mouse embryogenesis. Development. 1995; 121:1099-1110. [PubMed: 7743923]

9. Edom-Vovard F, Schuler B, Bonnin MA, Teillet MA, Duprez D. Fgf4 positively regulates scleraxis and tenascin expression in chick limb tendons. Developmental biology. 2002; 247:351-366. [PubMed: 12086472]

10. Schweitzer R, Chyung JH, Murtaugh LC, Brent AE, Rosen V, Olson EN, et al. Analysis of the tendon cell fate using Scleraxis, a specific marker for tendons and ligaments. Development. 2001; 128:3855-3866. [PubMed: 11585810]

11. Brent AE, Schweitzer R, Tabin CJ. A somitic compartment of tendon progenitors. Cell. 2003; 113:235-248. [PubMed: 12705871]

12. Brent AE, Tabin CJ. FGF acts directly on the somitic tendon progenitors through the Ets transcription factors Pea3 and Erm to regulate scleraxis expression. Development. 2004; 131:3885-3896. [PubMed: 15253939]

13. Shukunami C, Takimoto A, Oro M, Hiraki Y. Scleraxis positively regulates the expression of tenomodulin, a differentiation marker of tenocytes. Developmental biology. 2006; 298:234-247. [PubMed: 16876153]

14. Espira L, Lamoureux L, Jones SC, Gerard RD, Dixon IM, Czubryt MP. The basic helix-loop-helix transcription factor scleraxis regulates fibroblast collagen synthesis. Journal of molecular and cellular cardiology. 2009; 47:188-195. [PubMed: 19362560]

15. Smith TG, Sweetman D, Patterson M, Keyse SM, Munsterberg A. Feedback interactions between MKP3 and ERK MAP kinase control scleraxis expression and the specification of rib progenitors in the developing chick somite. Development. 2005; 132:1305-1314. [PubMed: 15716340]

16. Murchison ND, Price BA, Conner DA, Keene DR, Olson EN, Tabin CJ, et al. Regulation of tendon differentiation by scleraxis distinguishes force-transmitting tendons from muscle-anchoring tendons. Development. 2007; 134:2697-2708. [PubMed: 17567668]

17. Bagchi RA, Czubryt MP. Synergistic roles of scleraxis and Smads in the regulation of collagen 1alpha2 gene expression. Biochimica et biophysica acta. 2012; 1823:1936-1944. [PubMed: 22796342]

18. Levay AK, Peacock JD, Lu Y, Koch M, Hinton RB Jr, Kadler KE, et al. Scleraxis is required for cell lineage differentiation and extracellular matrix remodeling during murine heart valve formation in vivo. Circulation research. 2008; 103:948-956. [PubMed: 18802027]

19. Ng CM, Cheng A, Myers LA, Martinez-Murillo F, Jie C, Bedja D, et al. TGF-beta-dependent pathogenesis of mitral valve prolapse in a mouse model of Marfan syndrome. The Journal of clinical investigation. 2004; 114:1586-1592. [PubMed: 15546004]

20. Azhar M, Brown K, Gard C, Chen H, Rajan S, Elliott DA, et al. Transforming growth factor Beta2 is required for valve remodeling during heart development. Developmental dynamics : an official 
publication of the American Association of Anatomists. 2011; 240:2127-2141. [PubMed: 21780244]

21. Huk DJ, Hammond HL, Kegechika H, Lincoln J. Increased dietary intake of vitamin A promotes aortic valve calcification in vivo. Arteriosclerosis, thrombosis, and vascular biology. 2013; 33:285-293.

22. Lincoln J, Alfieri CM, Yutzey KE. BMP and FGF regulatory pathways control cell lineage diversification of heart valve precursor cells. Developmental biology. 2006; 292:292-302. [PubMed: 16680829]

23. Bueno OF, De Windt LJ, Tymitz KM, Witt SA, Kimball TR, Klevitsky R, et al. The MEK1ERK1/2 signaling pathway promotes compensated cardiac hypertrophy in transgenic mice. The EMBO journal. 2000; 19:6341-6350. [PubMed: 11101507]

24. Liang Q, De Windt LJ, Witt SA, Kimball TR, Markham BE, Molkentin JD. The transcription factors GATA4 and GATA6 regulate cardiomyocyte hypertrophy in vitro and in vivo. The Journal of biological chemistry. 2001; 276:30245-30253. [PubMed: 11356841]

25. Hulin A, Deroanne CF, Lambert CA, Dumont B, Castronovo V, Defraigne JO, et al. Metallothionein-dependent up-regulation of TGF-beta2 participates in the remodelling of the myxomatous mitral valve. Cardiovascular research. 2012; 93:480-489. [PubMed: 22180604]

26. Gould RA, Butcher JT. Isolation of valvular endothelial cells. Journal of visualized experiments : JoVE. 2010

27. Peacock JD, Levay AK, Gillaspie DB, Tao G, Lincoln J. Reduced sox9 function promotes heart valve calcification phenotypes in vivo. Circulation research. 2010; 106:712-719. [PubMed: 20056916]

28. Bosse K, Hans CP, Zhao N, Koenig SN, Huang N, Guggilam A, et al. Endothelial nitric oxide signaling regulates Notch1 in aortic valve disease. Journal of molecular and cellular cardiology. 2013; 60:27-35. [PubMed: 23583836]

29. Farhat YM, Al-Maliki AA, Chen T, Juneja SC, Schwarz EM, O'Keefe RJ, et al. Gene expression analysis of the pleiotropic effects of TGF-betal in an in vitro model of flexor tendon healing. PloS one. 2012; 7:e51411. [PubMed: 23251524]

30. Mendias CL, Gumucio JP, Lynch EB. Mechanical loading and TGF-beta change the expression of multiple miRNAs in tendon fibroblasts. J Appl Physiol. 2012; 113:56-62. [PubMed: 22539168]

31. Lorda-Diez CI, Montero JA, Martinez-Cue C, Garcia-Porrero JA, Hurle JM. Transforming growth factors beta coordinate cartilage and tendon differentiation in the developing limb mesenchyme. The Journal of biological chemistry. 2009; 284:29988-29996. [PubMed: 19717568]

32. Zhao B, Etter L, Hinton RB Jr, Benson DW. BMP and FGF regulatory pathways in semilunar valve precursor cells. Developmental dynamics : an official publication of the American Association of Anatomists. 2007; 236:971-980. [PubMed: 17326134]

33. Reznikoff CA, Bertram JS, Brankow DW, Heidelberger C. Quantitative and qualitative studies of chemical transformation of cloned $\mathrm{C} 3 \mathrm{H}$ mouse embryo cells sensitive to postconfluence inhibition of cell division. Cancer research. 1973; 33:3239-3249. [PubMed: 4796800]

34. Krenz M, Yutzey KE, Robbins J. Noonan syndrome mutation Q79R in Shp2 increases proliferation of valve primordia mesenchymal cells via extracellular signal-regulated kinase $1 / 2$ signaling. Circulation research. 2005; 97:813-820. [PubMed: 16166557]

35. Molin DG, Bartram U, Van der Heiden K, Van Iperen L, Speer CP, Hierck BP, et al. Expression patterns of Tgfbeta1-3 associate with myocardialisation of the outflow tract and the development of the epicardium and the fibrous heart skeleton. Developmental dynamics : an official publication of the American Association of Anatomists. 2003; 227:431-444. [PubMed: 12815630]

36. Robbins JR, Evanko SP, Vogel KG. Mechanical loading and TGF-beta regulate proteoglycan synthesis in tendon. Archives of biochemistry and biophysics. 1997; 342:203-211. [PubMed: 9186480]

37. Kretzschmar M, Doody J, Timokhina I, Massague J. A mechanism of repression of TGFbeta/ Smad signaling by oncogenic Ras. Genes \& development. 1999; 13:804-816. [PubMed: 10197981]

38. Hough C, Radu M, Dore JJ. Tgf-beta induced Erk phosphorylation of smad linker region regulates smad signaling. PloS one. 2012; 7:e42513. [PubMed: 22880011] 
39. Edom-Vovard F, Bonnin M, Duprez D. Fgf8 transcripts are located in tendons during embryonic chick limb development. Mechanisms of development. 2001; 108:203-206. [PubMed: 11578876]

40. Dietz HC, Cutting GR, Pyeritz RE, Maslen CL, Sakai LY, Corson GM, et al. Marfan syndrome caused by a recurrent de novo missense mutation in the fibrillin gene. Nature. 1991; 352:337-339. [PubMed: 1852208]

41. Loeys BL, Chen J, Neptune ER, Judge DP, Podowski M, Holm T, et al. A syndrome of altered cardiovascular, craniofacial, neurocognitive and skeletal development caused by mutations in TGFBR1 or TGFBR2. Nature genetics. 2005; 37:275-281. [PubMed: 15731757]

42. Matt P, Schoenhoff F, Habashi J, Holm T, Van Erp C, Loch D, et al. Circulating transforming growth factor-beta in Marfan syndrome. Circulation. 2009; 120:526-532. [PubMed: 19635970]

43. Holm TM, Habashi JP, Doyle JJ, Bedja D, Chen Y, van Erp C, et al. Noncanonical TGFbeta signaling contributes to aortic aneurysm progression in Marfan syndrome mice. Science. 2011; 332:358-361. [PubMed: 21493862]

44. Radermecker MA, Limet R, Lapiere CM, Nusgens B. Increased mRNA expression of decorin in the prolapsing posterior leaflet of the mitral valve. Interactive cardiovascular and thoracic surgery. 2003; 2:389-394. [PubMed: 17670080] 


\section{Highlights}

- Heart valves from Scx null mice have reduced proteoglycan expression.

- Scx is sufficient to promote proteoglycan expression in embryonic and mature heart valve interstitial cells.

- Tgf $\beta 2$ treatment promotes Scx expression in embryonic and mature heart valve interstitial cells.

- MAPK negatively regulates Scx-mediated regulation of proteoglycans

- Scx expression is increased in human patients and mouse models of myxomatous heart valve disease. 


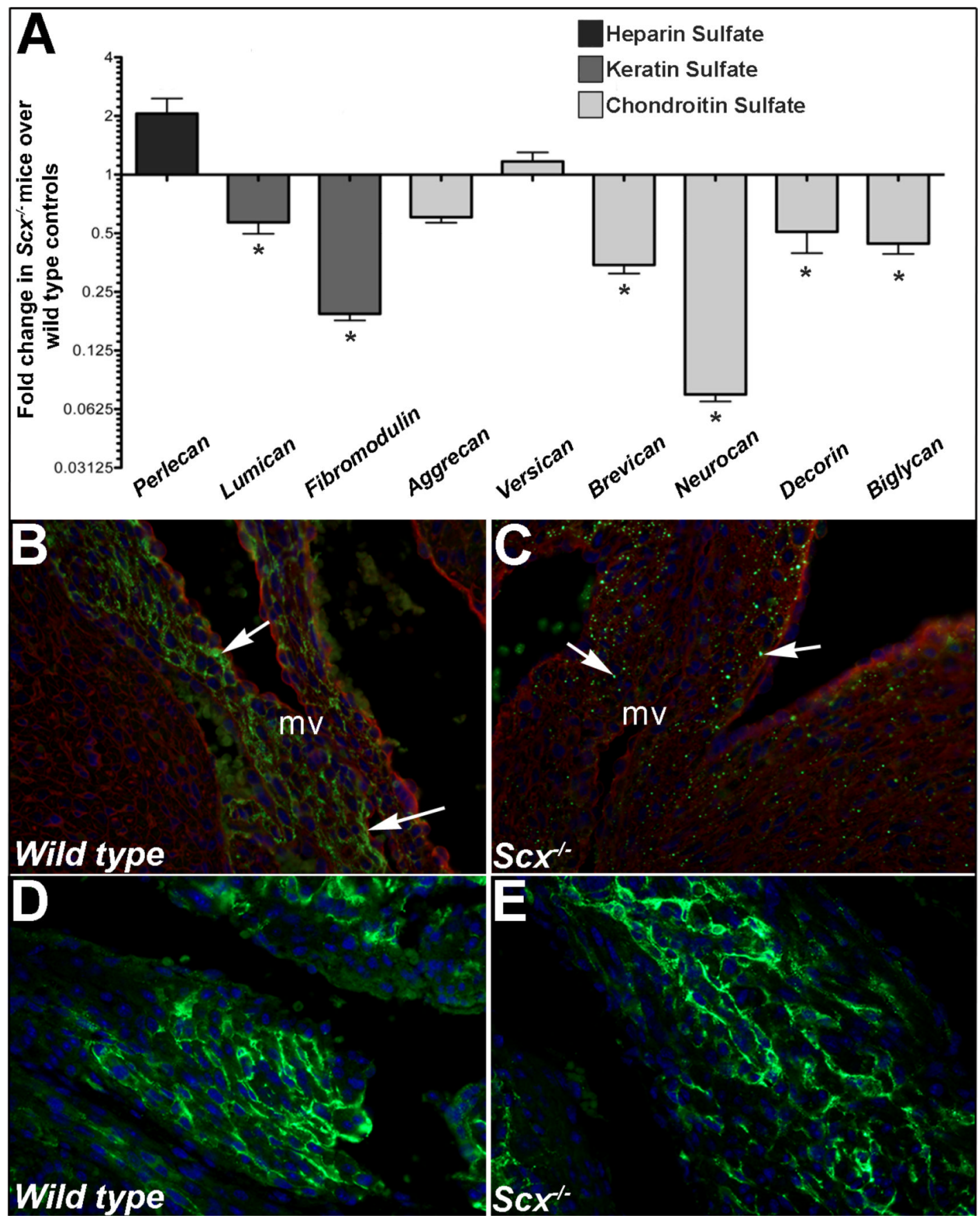

Figure 1. Proteoglycan expression is reduced in atrioventricular canal regions isolated from post natal $S c x^{-/-}$mice

(A) qPCR analysis to show fold changes in proteoglycan gene expression in atrioventricular canal regions isolated from post natal $S c x^{-/-}$mice compared to wild type littermate controls. * $\mathrm{p}<0.05$ using Student's t-test, $\mathrm{n}=4$. (B-E) Immunohistochemistry to detect chondroitin sulfate proteoglycan (CSPG) expression (green) in mitral valves (arrows, B, C) and atria (D, E) from post natal wild type $\left(S c x^{+/+}\right)(\mathrm{B}, \mathrm{D})$ and $S c x^{-/-}(\mathrm{C}, \mathrm{E})$ mice. Blue indicates DAPIstained cell nuclei, red indicates wheat germ agglutinin staining (cell membranes). mv, tricuspid valve. 


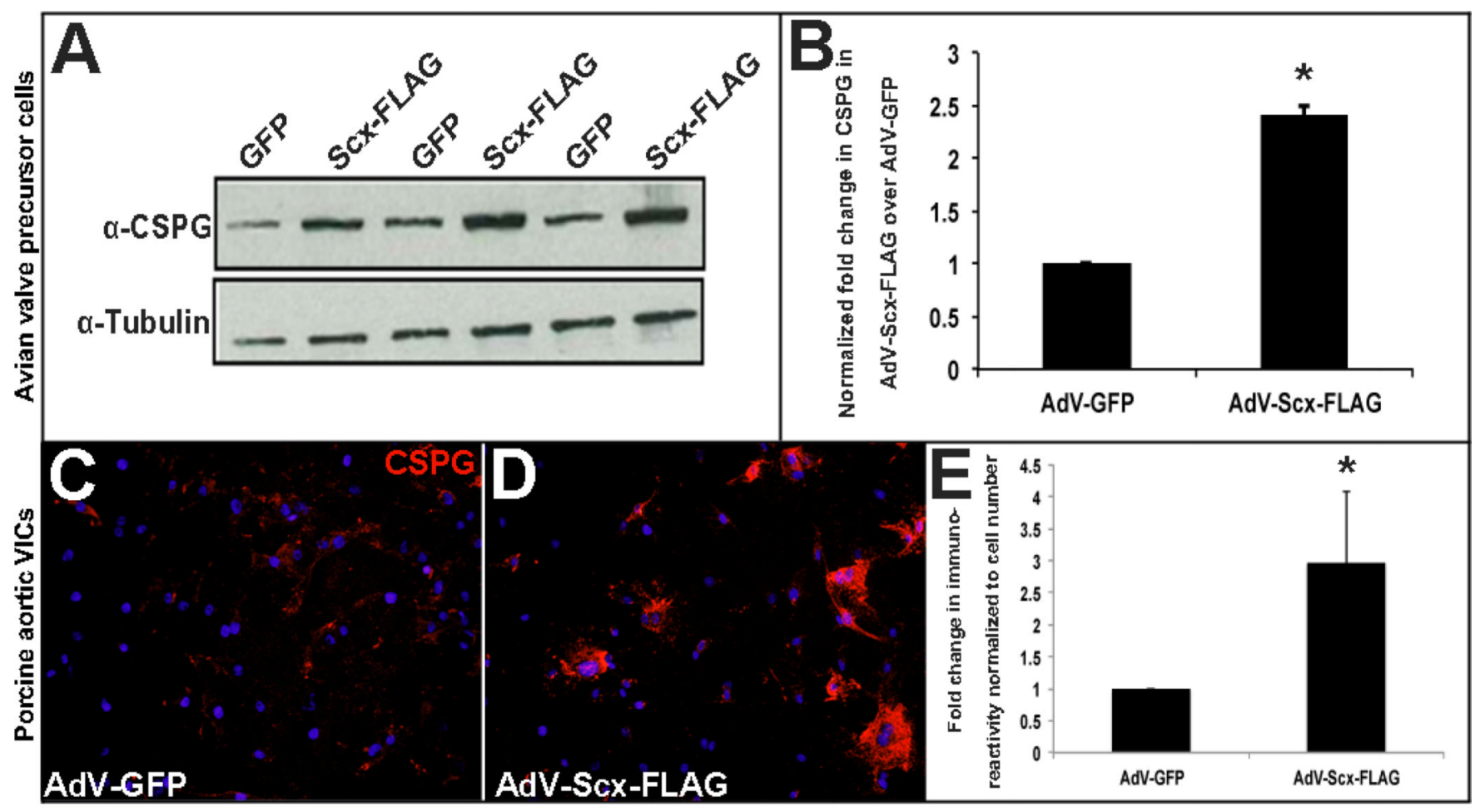

Figure 2. Scleraxis overexpression in avian valve precursor cells and porcine valve interstitial cells promotes chondroitin sulfate proteoglycan expression

(A) Western blot analysis to show CSPG expression in HH Stage 25 avian heart valve precursor cell cultures following 48 hour infection with AdV-Scx-FLAG (Scx-FLAG) or AdV-GFP (GFP). a-Tubulin was used as a loading control. (B) Densitometry quantitation of Western blot shown in (A), ${ }^{*}=\mathrm{p}<0.05$. (C-D) Immunohistochemistry to detect CSPG expression (red) in porcine valve interstitial (VICs) cultures infected with AdV-GFP or AdV-Scx-FLAG. Blue indicates DAPI-positive cell nuclei. (E) Quantitation of CSPG immunoreactivity shown in $\mathrm{C}-\mathrm{D}$ normalized to cell number per magnification field. $*=\mathrm{p}<0.05$ using Student's t-test, $\mathrm{n}=3$. 

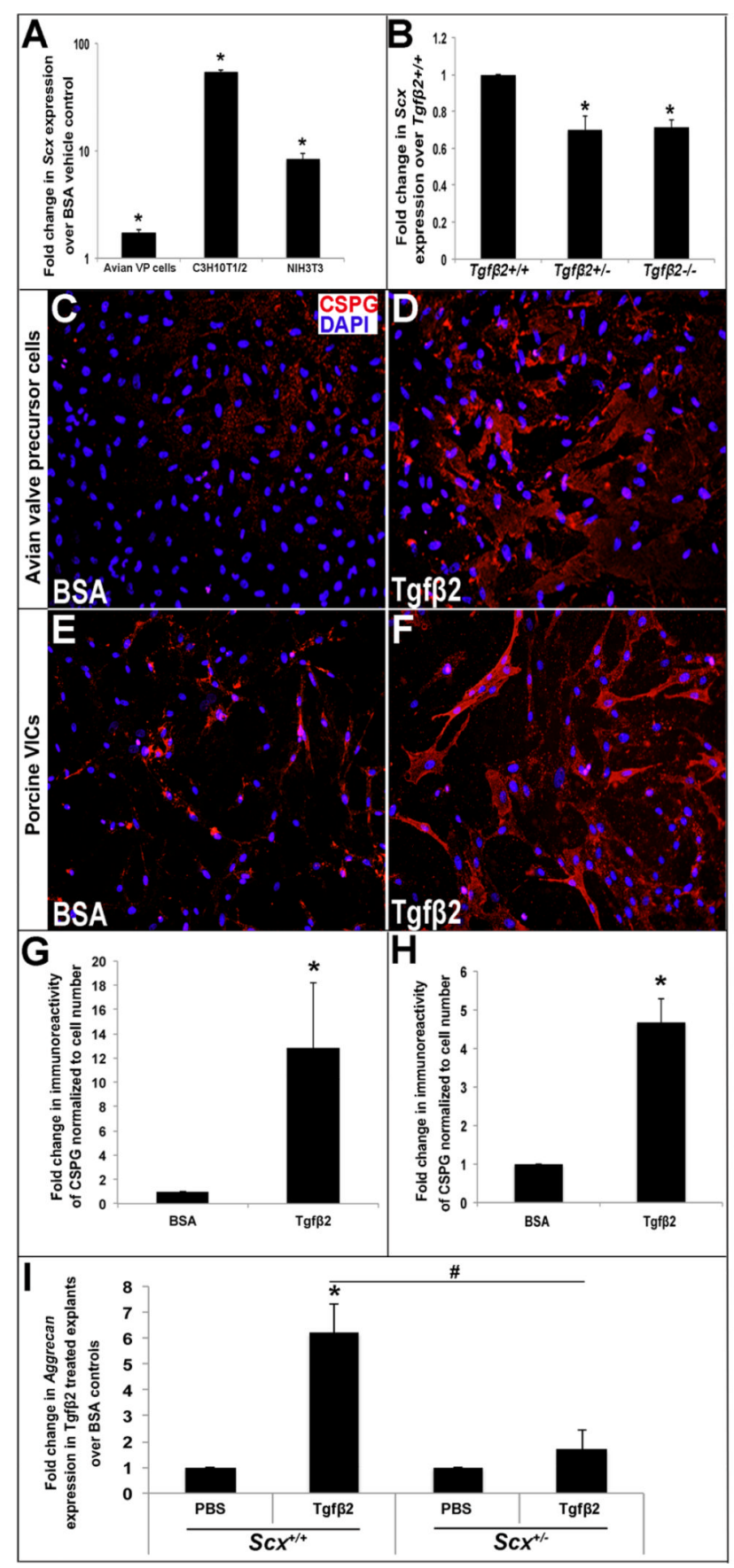

Figure 3. Tgf $\beta 2$ regulates $S c x$ expression in vitro and in vivo, and promotes chondroitin sulfate proteoglycan expression

(A) qPCR analysis to show fold changes in Scx expression in avian valve precursor cells, and $\mathrm{C}_{3} \mathrm{H}_{10 \mathrm{~T}_{1 / 2}}$ and NIH3T3 murine fibroblast cell lines treated with 200pM Tgf 32 for 48 hours compared to BSA vehicle treated controls $(n=3)$. (B) qPCR to show $S c x$ expression in E13.5 hearts from $T g f \beta 2^{+/-}$and $T g f \beta 2^{-/-}$mice compared to wild type $\left(T g f \beta 2^{+/+}\right)$littermate controls. (C-D) Immunohistochemistry to detect CSPG expression (red) in avian valve precursor cell cultures with BSA vehicle or 200pM Tgf $\beta 2$ treatment for 48 hours. (E-F) Immunohistochemistry to detect CSPG expression (red) in porcine VIC cultures treated for 48 hours with BSA vehicle or 200pM Tgf $\beta 2$. Blue indicates DAPI-positive cell nuclei. $(\mathrm{G}$, 
H) Quantitation of CSPG immunoreactivity in avian valve precursor cells (C, D) and porcine VICs (E, F) treated with 200pM Tgf $\beta 2$ compared to BSA control. $(*=p<0.05$ using oneway ANOVA plus a post-hoc test $\mathrm{n}=3$.) (I) qPCR to show fold changes in Aggrecan expression in mitral valve explants from $S c x^{+/+}$and $S c x^{-/-}$PND1 pups treated with Tgf $\beta 2$ treatment or PBS vehicle for 48 hours. $(*=p<0.05 \operatorname{Tgf} \beta 2$ versus PBS, $\#=p<0.05 \operatorname{Tgf} \beta 2$ treatment in $S c x^{+/+}$versus $S c x^{-/-}$using Students t-test, $\mathrm{n}=3$ ). 


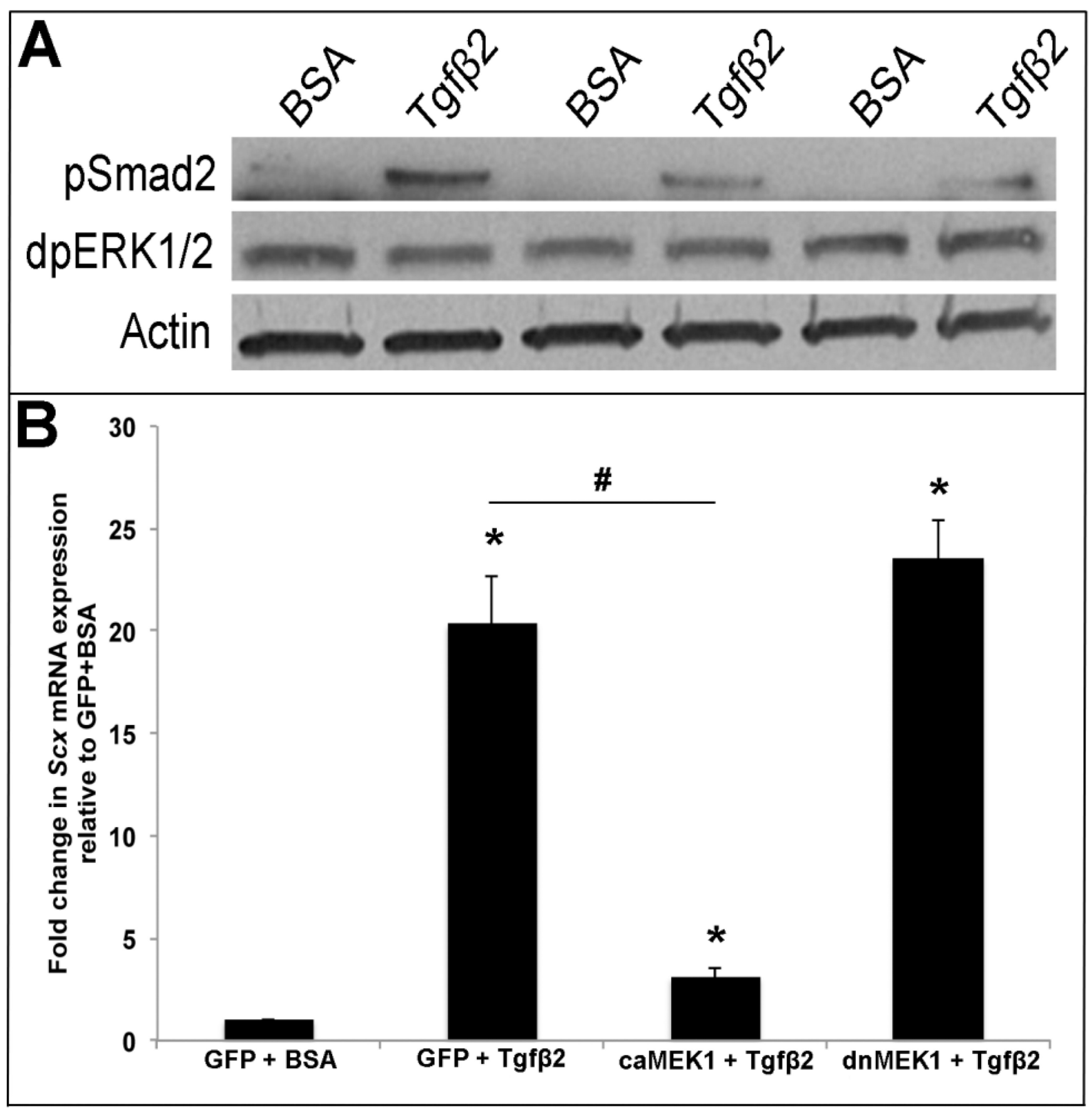

Figure 4. MEK1 activation represses Tgf $\beta 2$-mediated $S c x$ expression

(A) Western blot analysis to show phospho-Smad2 (pSmad) and diphosho-ERK1/2 (dpERK1/2) levels in avian valve precursor cell cultures treated with 200pM Tgf $\beta 2$ for 30 minutes, compared to BSA vehicle controls. Actin was used as a loading control (B) qPCR analysis to show $S c x$ expression in murine $\mathrm{C}_{3} \mathrm{H}_{10 \mathrm{~T}_{1 / 2}}$ cells pre-infected with AdV-GFP, AdV-caMEK1, or AdV-dnMEK1 for 6 hours prior to 48 hour treatment with 200pM Tgf 22 or BSA vehicle control. $*=\mathrm{p}<0.05$ vs. GFP+BSA, \#=p<0.05 vs. GFP+Tgf $\beta 2$ using one-way ANOVA plus a post-hoc test. 


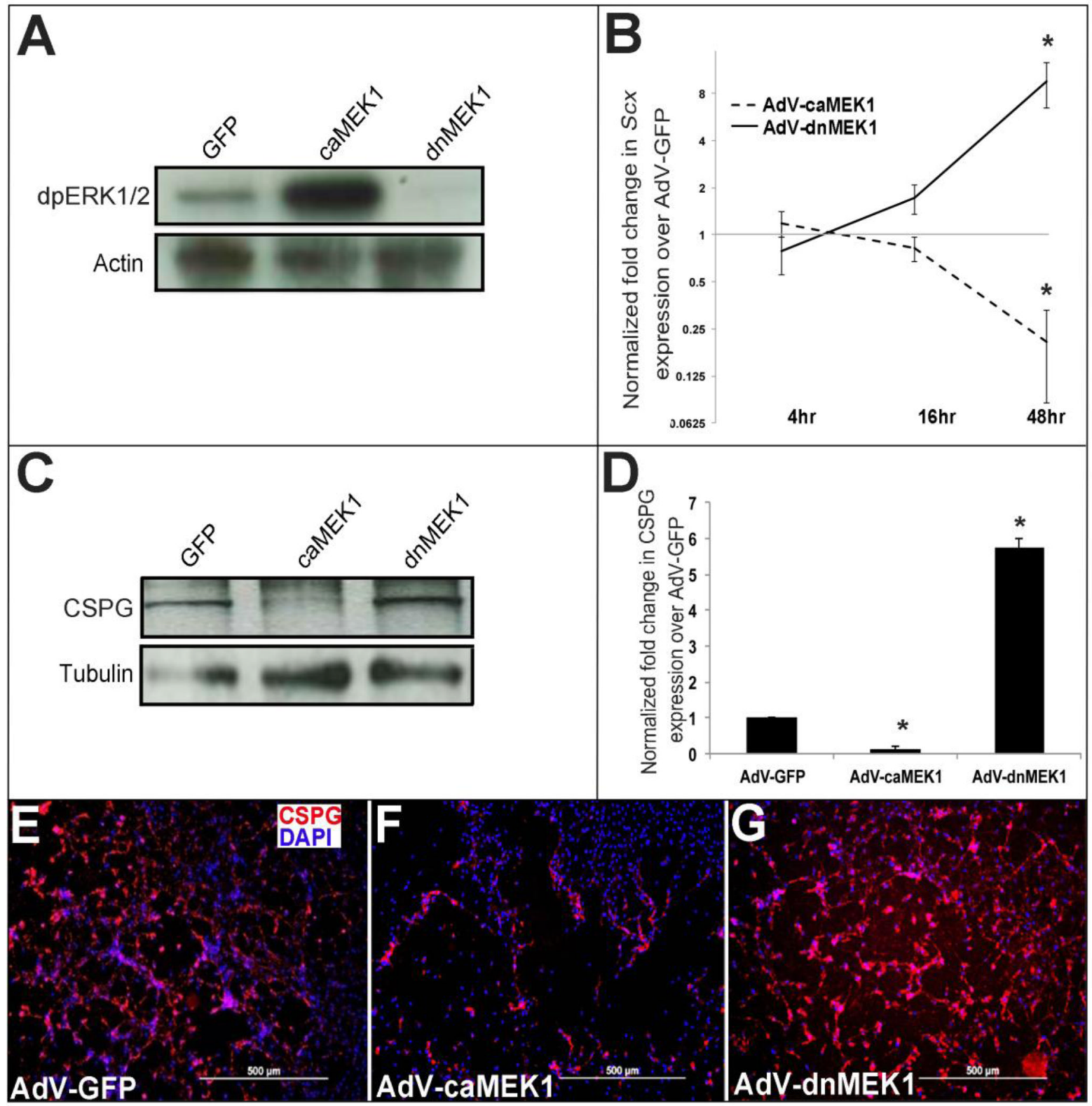

Figure 5. Activated MEK1 signaling represses $S c x$ and chondroitin sulfate proteoglycan expression in heart valve precursor cells

(A) Western blot analysis to show increased and decreased diphospho-ERK1/2 levels in avian heart valve precursor cells infected for 48 hours with AdV-caMEK1 and AdVdnMEK1 respectively, compared to AdV-GFP controls. (B) qPCR to show fold changes in Scx expression in avian valve precursor cells following AdV-caMEK1 and AdV-dnMEK1 infection for 4, 16 and 48 hours, compared to AdV-GFP controls $(n=4), *=p<0.05$. (C) Representative Western Blot to indicate CSPG expression in avian valve precursor cells following AdV-GFP, AdV-caMEK1 and AdV-dnMEK1 treatments for 48 hours. (D) Densitometry quantitation of Western blot analysis in $(\mathrm{C}),{ }^{*}=\mathrm{p}<0.05$ using one-way 
ANOVA plus a post-hoc test. (E-G) Immunohistochemistry to detect CSPG expression in avian VP cell cultures infected with AdV-GFP (E), AdV-caMEK1 (F) or AdV-dnMEK1 (G). 


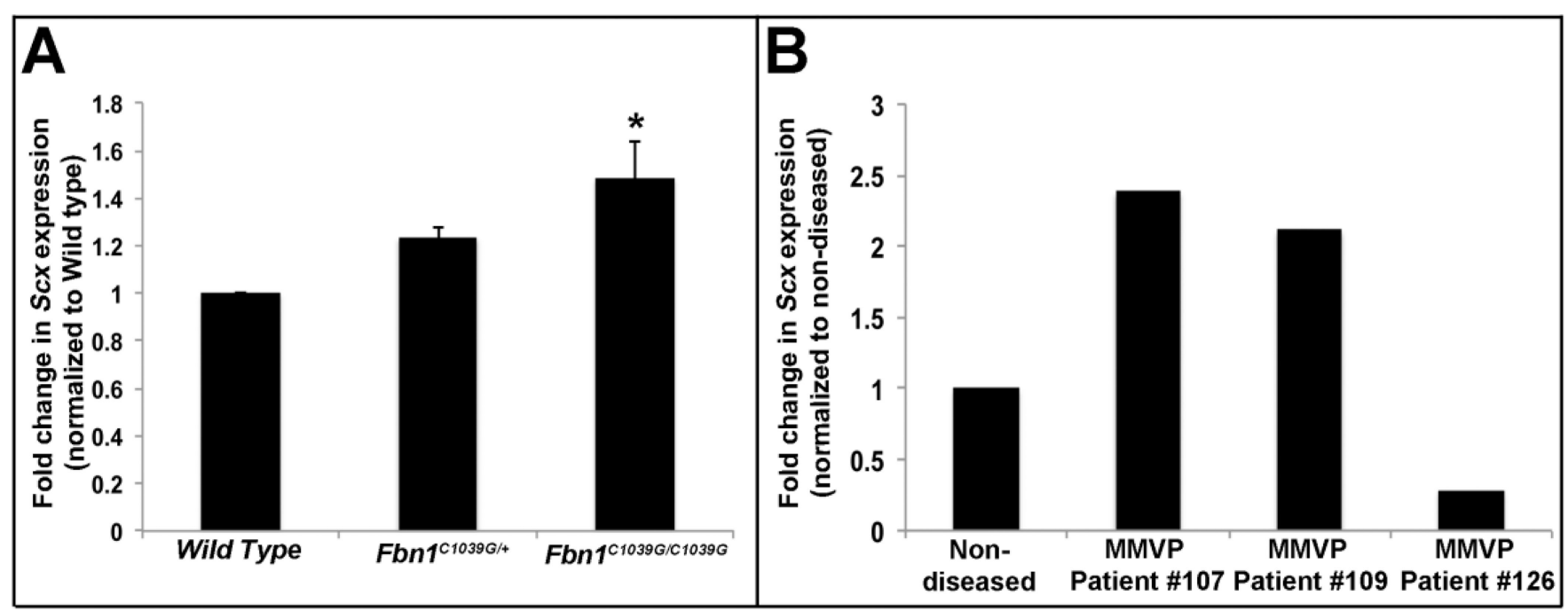

Figure 6. Scx is increased in myxomatous mitral valves (A) qPCR to show increased $S c x$ expression in atrioventricular canal regions isolated from PHD6 Fbn ${ }^{C 1039 G / C 1039 G}$ mice, compared to wild type littermate controls. (B) qPCR to show changes in $S c x$ expression in mitral VICs isolated from human patients diagnosed with myxomatous mitral valve disease, compared to mitral VICs collected from four, nondiseased hearts. $*=p<0.05$ using one-way ANOVA plus a post-hoc test. 


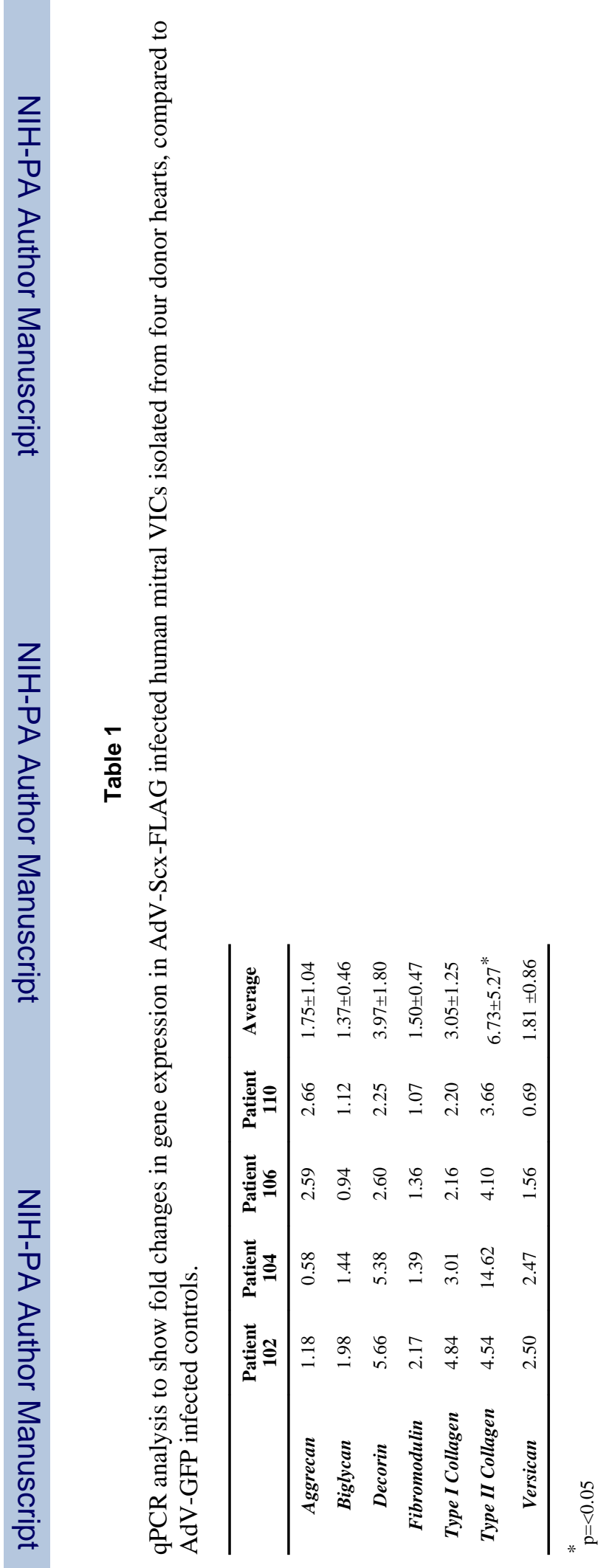

